\title{
INFLUÊNCIA DO PROCESSAMENTO DA FOLHA E TIPO DE SECAGEM NO TEOR E COMPOSIÇÃ̃O QUÍMICA DO ÓLEO ESSENCIAL DE MANJERICÃO cv. MARIA BONITA
}

\author{
Influence of leaf processing and type of drying on the content and chemical \\ composition of the essential oil of basil cv. Maria Bonita
}

\author{
Luciana Domiciano Silva Rosadoํㅜ José Eduardo Brasil Pereira Pinto², Priscila Pereira Botrel ${ }^{1}$, \\ Suzan Kelly Vilela Bertolucci ${ }^{1}$, Edenilson dos Santos Niculau ${ }^{3}$, Péricles Barreto Alves ${ }^{3}$
}

\begin{abstract}
RESUMO
O manjericão é uma planta medicinal aromática pertencente à família Lamiaceae, rica em óleos essenciais e com grande interesse industrial. Objetivou-se, no presente trabalho, estudar a influência do processamento da folha (inteira e pulverizada) submetida a dois tipos secagem (estufa de ventilação forçada a $38^{\circ} \mathrm{C}$ e sala com desumidificador), sobre o teor e composição química do óleo essencial. O delineamento utilizado foi o inteiramente casualizado (DIC), com 4 tratamentos e 6 repetições. O óleo essencial foi extraído por hidrodestilação das folhas e analisado por CG e CG/EM. O tipo de secagem e o processamento da folha do $O$. basilicum influenciaram no teor e composição química do óleo essencial. Maior porcentagem da área de pico do componente químico linalol foi obtida quando se realizou o processo de secagem das folhas. A secagem em estufa conservou o aroma e a coloração verde das folhas, preservando as características originais da cultivar.
\end{abstract}

Termos para indexação: Composição química, planta medicinal.

\section{ABSTRACT}

Ocimum basilicum L. cv. Maria Bonita is a medicinal aromatic plant of the Lamiaceae family, it is rich in essential oils with high industrial interest. The present work aimed to study the influence of leaf processing (whole and ground leaf) in two drying types (oven-drying at $38^{\circ} \mathrm{C}$ and room temperature using moisture dryer) on the content and chemical composition of the essential oil. A completely randomized design was used with 4 treatments and 6 replicates. The essential oil obtained by hydrodestillation of the leaves was analyzed by GC and GC/MS. The results show that the drying type and the processing of the leaf influence the content and chemical composition of the essential oil. High amounts of linalol were obtained when the leaves underwent dry processing. The oven-dried conserved the aroma and the green color of the leaves, preserving the original characteristics of the cultivar.

Index terms: Chemical composition, medicinal plants.

(Recebido em 18 de novembro de 2008 e aprovado em 7 de abril de 2010)

\section{INTRODUÇÃO}

O manjericão, Ocimum basilicum L., pertencente à família Lamiaceae, é uma planta anual originária do Sudoeste Asiático e da África Central, utilizada como planta medicinal, aromática, apresentando substâncias de interesse para as indústrias alimentícia, farmacêutica e cosmética (Matos \& Lorenzo, 2003).

Na medicina popular, as espécies de manjericão são indicadas como estimulante digestivo, antiespasmódico, gástrico, galactagogo, béquico, carminativo (Sajjadi, 2006). Estudos recentes têm demonstrado seu grande potencial antimicrobiano e antioxidante (Sartoratotto et al., 2004; Politeo et al., 2007).
As folhas secas de $O$. basilicum fazem parte da composição de temperos ou são utilizadas isoladamente na culinária, especialmente em massas. O óleo essencial é empregado para a produção de xampus, sabonetes e perfumes, apresentando também propriedades inseticidas e repelentes (Marotti et al., 1996; Umerie et al., 1998).

São diversos os fatores que podem acarretar mudanças no teor de óleo essencial, nas propriedades terapêuticas e condimentares como método de secagem, manejo pós-colheita, horário de colheita e local de cultivo (Cantwell \& Reid, 1994). A secagem, se não realizada adequadamente, pode comprometer o teor dos princípios ativos, uma vez que ela diminui a velocidade de deterioração do material, por meio da redução no teor de água, atuando

1 Universidade Federal de Lavras/UFLA - Lavras, MG

2Universidade Federal de Lavras/UFLA - Cx. P. 3037 - 37200-000 - Lavras, MG - jeduardo@dag.ufla.br

${ }^{3}$ Universidade Federal de Sergipe/UFS - São Cristovão, SE 
regressivamente na ação das enzimas, possibilitando a conservação das plantas por maior tempo.

Existem poucas informações dos agricultores e beneficiadores de plantas medicinais quanto ao processo de secagem, sendo esse muitas vezes realizado em temperaturas sem o controle devido ou na temperatura inadequada ao princípio ativo. Desse modo, o controle da qualidade pós-colheita das espécies medicinais, em relação ao processo de secagem, deve ser realizado de modo a não comprometer os princípios ativos das drogas vegetais, uma vez que o alto teor de umidade residual acima de $10 \%$ base úmida, favorece o desenvolvimento de fungos e bactérias, que possibilita a atividade hidrolítica de diversas enzimas, as quais podem comprometer tais princípios (Simões, 1999).

Devido ao valor econômico que o óleo essencial de manjericão apresenta no mercado atual é de fundamental importância estudos de pós-colheita com essa espécie obtida de melhoramento. O objetivo desse trabalho compreendeu o estudo da influência do processamento da folha e tipo de secagem sobre o teor e composição química do óleo essencial de manjericão (Ocimum basilicum L.) cultivar Maria Bonita.

\section{MATERIAL E MÉTODOS}

O trabalho foi conduzido no Laboratório de Cultura de Tecidos e Plantas Medicinais, Aromáticas e Condimentares ligado ao Departamento de Agricultura da UFLA. Sementes de Ocimum basilicum L. cv. Maria Bonita (PI197442-S3- bulk 13) preestabelecidas in vitro foram inoculadas em meio MS (Murashige \& Skoog, 1962). Após 30 dias, as plantas cultivadas in vitro foram aclimatizadas em bandejas de isopor contendo o substrato comercial Plantmax ${ }^{\circledR}$. Posteriormente, as plantas foram transplantadas para vasos de $10 \mathrm{~L}$ com areia, Plantmax ${ }^{\circledR} \mathrm{e}$ matéria orgânica, mantidas em casa de vegetação e irrigadas diariamente. Folhas foram colhidas de plantas com cerca de três meses de idade, às $8 \mathrm{~h}$ da manhã durante o período de floração.

Após a seleção e separação de materiais estranhos ao farmacógeno, esse foi submetido a dois métodos de secagem: (1) estufa de circulação forçada de ar a $38^{\circ} \mathrm{C}$ e (2), em sala escura com desumidificador a temperatura ambiente. As folhas foram acondicionadas em sacos de papel kraft para a secagem em estufa e na secagem por desumidificador as folhas foram distribuídas em bandejas com molduras de madeira e fundo de tela de sombrite. $\mathrm{O}$ término das secagens foi determinado pelo peso constante. Ao fim das secagens, realizou-se uma avaliação organoléptica das folhas, adotando-se como critérios o odor e a coloração.
O óleo essencial dos materiais vegetais oriundos de ambos os métodos de secagem foi extraído empregandose dois métodos de processamento: (1) folhas inteiras e (2) folhas pulverizadas em moinho de facas com malha de 20 mesh.

Para a extração, amostras de $40 \mathrm{~g}$ de folhas secas (inteiras ou pulverizadas) foram transferidas para balões de destilação de $2 \mathrm{~L}$, contendo 1,5 L de água destilada. A extração do óleo essencial foi realizada pelo processo de hidrodestilação, durante 90 min a partir da ebulição. Logo em seguida, o hidrolato foi submetido à partição líquidolíquido, em funil de separação, realizando-se três extrações do hidrolato com três porções de $15 \mathrm{~mL}$ de diclorometano por 10 min cada. As frações orgânicas foram reunidas e secas com sulfato de magnésio anidro, deixando-o agir por $30 \mathrm{~min}$; posteriormente, o sal foi removido por filtração simples e o solvente foi evaporado à temperatura ambiente sob capela de exaustão de gases. Diante da massa obtida, determinou-se o teor porcentual do óleo essencial pela fórmula: (T\% = Massa do óleo (g) x 100 / 40 g). Para a extração do óleo essencial de folhas frescas utilizou-se $80 \mathrm{~g}$, sendo a metodologia de extração a mesma descrita anteriormente.

$\mathrm{O}$ delineamento experimental utilizado foi $\mathrm{o}$ inteiramente casualizado (DIC), em esquema fatorial $2 \times 2$ (processamento do material vegetal e tipo de secagem), totalizando 4 tratamentos com 6 repetições, cada repetição composta por $40 \mathrm{~g}$ de material seco, correspondente a cada tipo de processamento e secagem. Os teores de óleo foram expressos em porcentagem em relação à matéria seca, os quais foram submetidos à ANOVA pelo teste de $\mathrm{F}(\mathrm{p}<0,05)$ e as médias dos tratamentos comparadas pelo de Tukey ( $\mathrm{p}<0,05)$, utilizando-se o software SISVAR, versão 5.0 (Ferreira, 2007).

As análises da composição química dos óleos essenciais foram realizadas no Laboratório de Cromatografia do Departamento de Química da Universidade Federal de Sergipe. Para essas análises empregou-se uma amostra composta, compreendida da reunião de alíquotas equivolumétricas do óleo volátil das seis repetições de cada tratamento.

As análises foram realizadas utilizando um sistema de cromatografia em fase gasosa acoplada a um espectrômetro quadrupolar de massas (CG-EM), Shimadzu ${ }^{\circledR}$ QP5050A (Kyoto, Japão), nas seguintes condições operacionais: coluna capilar de sílica fundida, modelo CBP-5 (30 m de comprimento x 0,25 mm de diâmetro interno $\mathrm{x} 0,25 \mu \mathrm{m}$ de espessura do filme em $5 \%$ de fenilmetilpolisiloxano) (Shimadzu ${ }^{\circledR}$, Japão), hélio como gás de arraste com fluxo de 1,0 $\mathrm{mL} / \mathrm{min}$; aquecimento com 
temperatura programada $\left(60^{\circ} \mathrm{C}\right.$ com uma rampa de temperatura de $3^{\circ} \mathrm{C} / \mathrm{min}$ até $240^{\circ} \mathrm{C}$ e, em seguida, com uma rampa de $10^{\circ} \mathrm{C} / \mathrm{min}$ até $270^{\circ} \mathrm{C}$, mantendo-se uma isoterma de $7 \mathrm{~min}$, compreendendo um tempo total de corrida de $70 \mathrm{~min}$ ). A energia de ionização do detector foi de $70 \mathrm{eV}$, sendo o volume de injeção da amostra de $0,5 \mu \mathrm{L}$ diluídas em diclorometano (grau ultra-resíduo, Baker, EUA) e uma razão de injeção de 1:20. As temperaturas do injetor e do detector foram mantidas em $220^{\circ} \mathrm{C}$ e $240^{\circ} \mathrm{C}$, respectivamente. A análise foi conduzida no modo varredura, a uma velocidade de $0,5 \mathrm{scan} / \mathrm{s}$, com um intervalo de aquisição de massas de $40-400 \mathrm{~m} / \mathrm{z}$. A análise quantitativa foi obtida pela integração do cromatograma total de íons. A identificação dos constituintes foi realizada por comparação dos espectros de massas com o banco de dados das bibliotecas NIST/EPA/NHI (National Institute of Standards and Technology - NIST, 1998) por comparação dos espectros de massas e índices de retenção (IR) com os da literatura (Adams, 2001) e coinjeção com padrões autênticos. Os IR foram calculados através da coinjeção com uma mistura de hidrocarbonetos, C8-C32 (Sigma, EUA), e com aplicação da equação de Dool \& Kratz (1963).

\section{RESULTADOS E DISCUSSÃO}

Com relação ao teor de óleo essencial, em função do processamento e tipo de secagem das folhas de manjericão, houve diferenças significativas $(\mathrm{p}<0,05)$ no teor de óleo essencial para folha inteira e moída provenientes da secagem em estufa de ventilação forçada de ar. Na secagem em estufa, as folhas que permaneceram inteiras $(1,07 \%)$ apresentaram teores de óleo essencial superior em relação as que foram pulverizadas $(0,86 \%)$. Entretanto, a secagem em desumidificador, não apresentou diferenças nos teores de óleos essenciais nos dois processamentos avaliados (Tabela 1).

Em plantas de capim limão (Cymbopogon citratus), Costa et al. (2005) relataram o efeito de diferentes métodos de secagem no teor de óleo essencial de folhas, verificando que a secagem em estufa, utilizando folhas inteiras resultou em menor teor de óleo essencial nessa espécie, em comparação com a secagem em desumidificador.

De maneira semelhante, Corrêa et al. (2004) estudando o efeito da secagem (estufa a $35^{\circ} \mathrm{C}$, secador solar a $32^{\circ} \mathrm{C}$, secagem mista a $27^{\circ} \mathrm{C}$ e secagem à sombra a $25^{\circ} \mathrm{C}$ ), constataram que o menor teor de óleo essencial de Vernonia polyanthes Less. ocorreu na secagem realizada em estufa.

De acordo com Araújo (2004), as características organolépticas podem ser dadas pelos componentes majoritários e que o alto teor de monoterpenos presente na composição de um óleo essencial implica num produto instável, sensível à luz e ao calor. Esse fato pode ser observado no óleo essencial do manjericão cv. Maria Bonita, que apresenta como compostos majoritários o linalol, o geraniol e o 1,8 cineol (Figura 1) que, somados, representam mais de $95,16 \%$ de todos os componentes químicos presentes no óleo essencial (Blank et al., 2007).

Ao analisar as características organolépticas, a cultivar Maria Bonita apresentou aroma agradável e forte, característico da planta, coloração incolor e baixa viscosidade. Também foi observado nos materiais secos em estufa, um aroma mais intenso quando comparados à secagem promovida pelo desumidificador. A secagem das folhas em estufa foi mais rápida, preservando a coloração verde das folhas, com isso conservando o cheiro característico da espécie. Ao utilizar o desumidificador, o tempo de secagem foi maior e as folhas apresentaram manchas escuras, provavelmente devido à alta umidade no período de condução do experimento.

Resultado semelhante foi observado por Costa et al. (1999) quando avaliaram a secagem das folhas de guaco utilizando dois secadores: estufa e câmara com desumidificador, concluindo que a secagem em estufa conserva a coloração esverdeada das folhas e resulta em melhor qualidade quanto às características organolépticas.

Radünz et al. (2002), que a observaram secagem em temperatura ambiente em relação à secagem em estufa, provocou alterações na coloração e no odor das folhas de alecrim pimenta (Lippia sidoides Cham.), e que essas foram provocadas provavelmente pelo período maior de secagem e desenvolvimento de fungos.

Resultados contrários foram observados por Costa et al. (2005), concluindo que a secagem em desumidificador promove a desidratação do material vegetal apenas pela redução da umidade do ar sem elevação da temperatura do ambiente, preservando as características originais da planta.

No que se refere à composição química do óleo essencial em função dos tipos de processamentos e secagem, notam-se poucas diferenças entre os tratamentos (Tabela 2).

O óleo essencial de $O$. basilicum apresentou, predominantemente, monoterpenos oxigenados. As análises cromatográficas permitiram identificar no óleo essencial a presença de monoterpenos (1,8-cineol, $\alpha$-terpineol, geraniol e linalol) e sesquiterpenos (acetato de isobornila, acetato de geranila, $\alpha$-trans-bergamoteno, $\gamma$-muuroleno, $\gamma$-cadieno e epi- $\alpha$-cadinol). Dentre esses constituintes, o linalol e o geraniol foram os majoritários (Tabela 2). 
Tabela 1 - Teores (\%) médios de óleo essencial de Ocimum basilicum L. em função de métodos de secagem e processamento da folha.

\begin{tabular}{lcc}
\hline \multirow{2}{*}{ Secagem } & \multicolumn{2}{c}{ Teor (\%) de óleo essencial na folha } \\
\cline { 2 - 3 } & Inteira & Pulverizada \\
\hline Estufa & $1,07 \mathrm{a} \mathrm{A}$ & $0,86 \mathrm{a} \mathrm{B}$ \\
Desumidificador & $0,87 \mathrm{~b} \mathrm{~A}$ & $0,94 \mathrm{a} \mathrm{A}$ \\
\hline
\end{tabular}

*Médias seguidas da mesma letra minúscula na coluna e maiúscula na linha, não diferem entre si, a 5\% de probabilidade pelo teste de Tukey.<smiles>C=CC(C)(O)CCC=C(C)C</smiles>

Linalol<smiles>CC(C)=CCCC(C)=CCO</smiles>

Geraniol<smiles>CC12CCC(CC1)C(C)(C)O2</smiles>

1,8-cineol

Figura 1 - Estruturas dos principais componentes monoterpenos presentes no óleo essencial de Ocimum basilicum L.

Tabela 2 - Percentagem da área relativa dos picos cromatográficos correspondentes aos compostos identificados no óleo essencial de Ocimum basilicum L., em função de métodos de secagem e processamento da folha.

\begin{tabular}{cccccccc}
\hline \multirow{2}{*}{ IK } & \multirow{2}{*}{ Constituintes } & \multirow{2}{*}{ Classe } & Folhas & \multicolumn{3}{c}{ Estufa } & \multicolumn{2}{c}{ Desumidificador } \\
\cline { 5 - 8 } & & frescas & Pulverizada & Inteira & Pulverizada & Inteira \\
\hline 1032 & 1,8 -cineol & $\mathrm{M}$ & 1,12 & 0,55 & 0,73 & 0,45 & 0,37 \\
1099 & linalol & $\mathrm{M}$ & 78,35 & 81,69 & 80,85 & 84,34 & 82,21 \\
1194 & $\alpha$-terpineol & $\mathrm{M}$ & 0,59 & 0,79 & 0,83 & 0,75 & 0,81 \\
1250 & geraniol & $\mathrm{M}$ & 15,94 & 12,41 & 14,37 & 12,17 & 13,85 \\
1284 & acetato de iso-bornila & $\mathrm{S}$ & - & - & 0,25 & 0,24 & 0,27 \\
1378 & acetato de geranila & $\mathrm{S}$ & 1,7 & 1,59 & 1,42 & 1,09 & 1,39 \\
1432 & $\alpha$-trans-bergamoteno & $\mathrm{S}$ & 0,7 & 1,16 & 0,58 & 0,5 & 0,51 \\
1780 & $\gamma$-muuroleno & $\mathrm{S}$ & - & 0,4 & - & - & - \\
1512 & $\gamma$-cadineno & $\mathrm{S}$ & 0,2 & 0,49 & 0,24 & - & - \\
1641 & epi- $\alpha$-cadinol & $\mathrm{S}$ & 1,4 & 0,87 & 0,68 & 0,42 & 0,54 \\
\hline Monoterpenos totais $(\mathrm{M})$ & & 96,0 & 95,44 & 96,78 & 97,71 & 97,24 \\
\hline Sesquiterpenos totais $(\mathrm{S})$ & & 4,0 & 4,51 & 3,17 & 2,25 & 2,71 \\
\hline Total dos Picos & & 100 & 99,95 & 99,95 & 99,96 & 99,95 \\
\hline
\end{tabular}

IK: Índices de Kovats calculados.

Diferenças na porcentagem da área de picos referentes à composição química do óleo essencial de folhas frescas e secas foram observadas. $\mathrm{O}$ teor de linalol sofreu um aumento na porcentagem de área do pico quando as folhas foram submetidas à secagem, independente do método empregado (estufa ou desumidificador). Por outro lado, o geraniol e o 1,8cineol apresentaram quedas em seus teores quando se compara o material fresco com os materiais vegetais secos. 
Essa queda nos teores foi mais expressiva para o 1,8-cineol. Segundo pesquisas desenvolvidas por Semikolenov et al. (2003) o geraniol é convertido em linalol pelo processo de isomerização, uma vez que estes compostos são muito sensíveis à temperatura. Provavelmente, isso deve ter ocorrido no processo de secagem das folhas de manjericão.

O linalol é o constituinte químico majoritário presente no óleo essencial dessa espécie, apresentando teores na faixa de 78,3 a 84,3\%. A faixa porcentual de linalol demonstra que, para esse constituinte, não há diferenças consideráveis entre os métodos de secagem e processamento para obtenção do óleo essencial de manjericão. Ao contrário, outros constituintes demonstraram diferenças superiores a $50 \%$ no teor relativo, como ocorreram com o $\alpha$-transbergamoteno $(0,50 \%$ para $1,16 \%)$ e o epi- $\alpha$-cadinol $(0,42 \%$ para $0,87 \%)$ nas folhas pulverizadas submetidas à secagem em desumificador e em estufa, respectivamente (Tabela 2).

Entre os dois tipos de secagem, a diferença principal na composição química do óleo essencial foi a presença dos compostos $\gamma$-muuroleno e $\gamma$-cadineno que não foram detectados nas folhas pulverizadas e inteiras, quando secas em desumidificador. Por outro lado, o acetato de iso-bornila não foi detectado na folha moída, enquanto o $\gamma$-muuroleno não foi detectado na folha inteira, ambas secas em estufa. A secagem em estufa garantiu melhor preservação dos constituintes do $O$. basilicum L., quando comparada à secagem em desumidificador.

Resultados divergentes foram obtidos por Asekun et al. (2007), estudando os efeitos de diferentes métodos de secagem (ao ar, sol e forno) na qualidade e quantidade do óleo essencial de Mentha longifolia L.. Observou-se que os teores de monoterpenos totais de folhas secas ao ar $(93,3 \%)$ e ao sol $(91,8 \%)$ apresentaram porcentuais similares aos teores das folhas frescas $(92 \%)$, mas quando secaram as folhas no forno o conteúdo diminuiu para $63,5 \%$.

As mudanças nas concentrações dos constituintes voláteis dependem de vários fatores tais como método de secagem e espécie de planta. $\mathrm{O}$ manjericão pertencente à família Lamiaceae, armazena seus óleos essenciais próximos à superfície das folhas (Moyler, 1994). Pressupõe-se que temperaturas menores no desumidificador poderiam contribuir para uma menor degradação das células oleíferas e consequentemente, preservar os componentes químicos do óleo, fato esse não observado para o manjericão cv. Maria Bonita.

\section{CONCLUSÕES}

O tipo de secagem e processamento da folha influencia no teor e composição química do óleo essencial de manjericão.
A secagem em estufa conservou as características organolépticas do manjericão, quanto ao aroma e coloração verde das folhas.

Maiores quantidades de linalol foram obtidas nas folhas submetidas ao processo de secagem.

Os componentes majoritários do óleo essencial de Ocimum basilicum L., nos devidos tratamentos, foram o linalol e o geraniol.

\section{AGRADECIMENTOS}

Ao Conselho Nacional de Desenvolvimento Científico (CNPq), à Coordenação de Aperfeiçoamento de Pessoal de Nível Superior (Capes) e à FAPEMIG, pela concessão da bolsa de estudo e suporte financeiro.

\section{REFERÊNCIAS BIBLIOGRÁFICAS}

ADAMS, R.P. Identification of essential oil components by gas chromatography/quadrupole mass sprestroscopy. Allured: Illinois, 2001. 421p.

ARAÚJO, J.M.A. Química de alimentos: teoria e prática. 3.ed. Viçosa, MG: UFV, 2004. 416p.

ASEKUN, O.T.; GRIERSON, D.S.; AFOLAYAN, A.J. Effects of drying methods on the quality and quantity of the essential oil of Mentha longifolia L. subsp. Capensis. Food Chemistry, Oxford, v.101, p.995-998, 2007.

BLANK, A.F.; SOUZA, V.M.; ARRIGONI-BLANK, M.F.; PAULA, J.W.A.; ALVES, P.B. Novas Cultivares Maria Bonita: cultivar de manjericão tipo linalol. Pesquisa Agropecuária Brasileira, Brasília, v.42, n.12, p.18111813, nov. 2007.

CANTWELL, M.I.; REID, M.S. Postharvest physiology and handling of fresh culinary herbs. Journal of Herbs, Spices \& Medicinal Plants, Amherst, v.1, n.3, 1994.

CORRÊA, R.M.; BERTOLUCCI, S.K.V.; PINTO, J.E.B.P.; REIS, É.S.; ALVES, T.L. Rendimento de óleo essencial e caracterização organoléptica de folhas de assa-peixe submetidas a diferentes métodos de secagem. Ciência e Agrotecnologia, Lavras, v.28, n.2, p.339-344, mar./abr. 2004.

COSTA, C.C.; CASALI, V.W.D.; MACEDO, J.A.B. Qualidade de folhas de guaco (Mikania glomerata Sprengel) após secagem e embalagem. Revista

Brasileira de Plantas Medicinais, Botucatu, v.1, n.2, p.1-5, 1999. 
COSTA, L.C.B.; CORRÊA, R.M.; CARDOSO, J.C.W.; PINTO, J.E.B.P.; BERTOLUCCI, S.K.V.; FERRI, P.H.

Secagem e fragmentação da matéria seca no rendimento e composição do óleo essencial de capim-limão. Horticultura Brasileira, Brasília, v.23, n.4, p.956-959, out./dez. 2005.

DOOL, H. van den; KRATZ, P.D. A generalization of the retention index system including linear temperature programmed gas-liquid partition chromatography. Journal of Chromatography A, Amsterdam, v.11, p.463471, 1963.

FERREIRA, D.F. SISVAR 5.0: sistema de análise estatística. Lavras: UFLA, 2007. Software.

MAROTTI, M.; PICCAGLIA, R.; GIOVANELLI, E. Differences in essential oil composition of Basil (Ocimum basilicum L.) italian cultivars related to morphological characteristics. Journal of Agricultural Food Chemistry, Washington, v.44, n.12, p.3926-3929, 1996.

MATOS, F.J.A.; LORENZO, H. Plantas medicinais do Brasil: nativas e exóticas cultivadas. Nova Odessa: Instituto Plantarum, 2003. 544p.

MOYLER, D.A. Spices: recent advances. In: CHARALAMBOUS, G. Spices, herbs and edible fungi. Amsterdam: Elsevier, 1994. p.1-70.

MURASHIGE, T.; SKOOG, F. A revised medium for rapid growth and bioassays with tobacco cultures. Physiologia Plantarum, Copenhagen, v.15, p.473-497, 1962.

NATIONAL INSTITUTE OF STANDARDS AND TECHNOLOGY. PC version of the NIST/ EPA/NIH Mass Spectral Database. Gaithersburg, 1998.
POLITEO, O.; JUKIC, M.; MILOS, M. Chemical composition and antioxidant capacity of free volatile aglycones from basil (Ocimum basilicum L.) compared with its essential oil. Food Chemistry, Oxford, v.101, n.1, p.379-385, 2007.

RADÜNZ, L.L.; MELO, E.C.; MARTINS, P.M.; SANTOS, R.H.S.; SANTOS, R.R.; MACHADO, M.C. Secagem de alecrim pimenta (Lippia sidoides Cham.) em secador de leito fixo. Revista Brasileira de Plantas Medicinais, Botucatu, v.5, n.1, p.79-82, out. 2002.

SAJJADI, S.E. Analysis of the essential oil of two cultivated basil (Ocimum basilicum L.) from Iran. Daru, Iran, v.14, n.3, p.128-130, 2006.

SARTORATOTTO, A.; MACHADO, A.L.M.; DELARMELINA, C.; FIGUEIRA, G.M.; DUARTE, M.C.T.; REHDER, V.L.G. Composition and antimicrobial activity of essential oils from aromatic plants used in Brazil. Brazilian Journal of Microbiology, São Paulo, v.35, p.275-280, Oct./Dec. 2004.

SEMIKOLENOV, V.A.; ILYNA, I.I.; MAKSIMOVSKAYA, R.I. Linalool to geraniol/nerol isomerization catalyzed by $(\mathrm{RO})_{3} \mathrm{VO}$ complexes: studies of kinetics and mechanism. Journal of Molecular Catalysis A: Chemical, v.204/205, p.201-210, Sept. 2003.

SIMÕES, D.E. Farmacognosia: da planta ao medicamento. São Paulo: Atheneu, 1999. 540p.

UMERIE, S.C.; ANASO, H.U.; ANYASORO, L.J.C. Inseticidal potentials of Ocimum basilicum leaf extracts. Bioresource Technology, Oxon, v.64, n.3, p.237-239, 1998. 